01

\title{
Structural, spectroscopic, antimictobial activity and DFT studies
} on 4-methyl-N-(4-methylphenylsulfonyl)-N-phenylbenzenesulfonamide*

\author{
(C) Bilge Eren ${ }^{1}$, Fadime Özdemir Kocak ${ }^{2}$, Namık Özdemir ${ }^{3}$ \\ ${ }^{1}$ Department of Chemistry, Faculty of Arts and Sciences, Bilecik Şeyh Edebali University, \\ 11210 Bilecik, Turkey \\ ${ }^{2}$ Department of Nursing, School of Health, Bilecik Şeyh Edebali University, \\ 11210 Bilecik, Turkey \\ ${ }^{3}$ Department of Mathematics and Science Education, Faculty of Education, Ondokuz Mayıs University, \\ 55139 Samsun, Turkey \\ "e-mail: namiko@omu.edu.tr
}

Received October 1, 2017

This study reports the structural characterization of a disulfonimide derivative, 4-methyl-N-(4-methylphenylsulfonyl)-N-phenylbenzenesulfonamide (MPBSA), using spectroscopic and quantum chemical methods. The molecule was characterized with FT-IR, ${ }^{1} \mathrm{H}^{13} \mathrm{C}-\mathrm{NMR}$ and UV-Vis spectroscopies. Quantum chemical calculations of molecular geometry, vibrational wavenumbers and gauge including atomic orbital (GIAO) ${ }^{1} \mathrm{H}$ and ${ }^{13} \mathrm{C}-\mathrm{NMR}$ chemical shifts of the compound were carried out by using density functional method (DFT) at B3LYP/6-311++G(d,p) level of theory. Electronic absorption spectra of the compound have been computed using the time-dependent density functional theory (TD-DFT) method at the same level. A satisfactory consistency between the experimental and theoretical findings was obtained. The antimicrobial activity screening of the compound was performed on some bacteria and fungus species using microdilution method. The results showed that the title molecule have noteworthy antibacterial and antifungal activities.

DOI: $10.21883 /$ OS.2018.07.46260.222-17

* Полный текст статьи опубликован в английской версии журнала. 